\title{
Diastolic Dysfunction in Hypertrophic Cardiomyopathy Effect on Active Force Generation During Systole
}

\author{
Judith K. Gwathmey, Sanford E. Warren, G. Maurice Briggs, Linda Copelas, Marc D. Feldman, Preston J. Phillips, \\ Mark Callahan, Jr., Frederick J. Schoen, William Grossman, and James P. Morgan \\ From the Charles A. Dana Research Institute and Harvard-Thorndike Laboratory of Beth Israel Hospital; the Consolidated Department \\ of Medicine (Cardiovascular Divisions) and Departments of Pathology, Beth Israel and Brigham and Women's Hospitals; the Division \\ of Cardiovascular Surgery, Brigham and Women's Hospital, Boston, MA 02215; and the Departments of Pharmacology \\ and Medicine (Cardiovascular Division) and the Division of Cardiothoracic Surgery, Mayo Medical School \\ and Mayo Graduate School of Medicine, Rochester, Minnesota 55905
}

\section{Abstract}

We tested the hypothesis that intracellular $\mathrm{Ca}^{++}\left(\left[\mathrm{Ca}^{++}\right]_{\mathrm{i}}\right)$ overload underlies the diastolic dysfunction of patients with hypertrophic cardiomyopathy. Myocardial tissue was obtained at the time of surgery or transplantation from patients with hypertrophic cardiomyopathy and was compared with control myocardium obtained from patients without heart disease. The isometric contractions and electrophysiologic properties of all myocardial specimens were recorded by standard techniques and $\left[\mathrm{Ca}^{++}\right]_{\mathbf{i}}$ was measured with the bioluminescent calcium indicator aequorin. In contrast to the controls, action potentials, $\mathrm{Ca}^{++}$ transients, and isometric contraction and relaxation were markedly prolonged in the hypertrophic myocardium, and the $\mathrm{Ca}^{++}$ transients consisted of two distinct components. At $38^{\circ} \mathrm{C}$ and 1 $\mathrm{Hz}$ pacing frequency, a state of relative $\mathrm{Ca}^{++}$overload appeared to develop, which produced a rise in end-diastolic $\left[\mathrm{Ca}^{++}\right]_{i}$, incomplete relaxation, and fusion of twitches with a resultant decrease in active tension development. We also found that drugs which increase $\left[\mathrm{Ca}^{++}\right]_{i}$, such as digitalis, exacerbated these abnormalities, whereas drugs that lower $\left[\mathrm{Ca}^{++}\right]_{i}$, such as verapamil, or agents that increase cyclic AMP, such as forskolin, prevented them. These results may explain why patients with hypertrophic cardiomyopathy tolerate tachycardia poorly, and may have important implications with regard to the pharmacologic treatment of patients with hypertrophic cardiomyopathy. (J. Clin. Invest. 1991. 87:1023-1031.) Key words: calcium indicators $\bullet$ diastolic dysfunction $\cdot$ hypertrophic cardiomyopathy - sarcoplasmic reticulum - cyclic adenosine monophosphate

\section{Introduction}

Hypertrophic cardiomyopathy is a disease of unknown etiology that is characterized anatomically by a small left ventricular cavity and marked hypertrophy of the myocardium with myocardial fiber disarray (1-3). An intraventricular pressure

Portions of this work have appeared in abstract form in 1986. Circulation. 74(Suppl):169; 1986. Circulation. 74(Suppl):290; and 1989. J. Cell. Biochem. 13E(Suppl):171.

Address correspondence and reprint requests to Dr. James P. Morgan, Cardiovascular Division, Beth Israel Hospital, 330 Brookline Avenue, Boston, MA 02215.

Received for publication 28 February 1990 and in revised form 25 July 1990

J. Clin. Invest.

(C) The American Society for Clinical Investigation, Inc. $0021-9738 / 91 / 03 / 1023 / 09 \$ 2.00$

Volume 87, March 1991, 1023-1031 gradient may or may not be present (4-6). A major problem in hypertrophic cardiomyopathy appears to be the severe hypertrophy and associated decrease in left ventricular diastolic relaxation and compliance.

Clinical studies have shown that patients with hypertrophic cardiomyopathy typically display symptoms and signs of diastolic dysfunction, such as dyspnea and elevated pulmonary capillary wedge pressure, due to impaired ventricular filling and slow decay of left ventricular pressure $(4,7-11)$. The basis of these diastolic abnormalities is probably multifactorial, but has been proposed to be due in large part to changes in intracellular $\mathrm{Ca}^{++}$handling by hypertrophied myocytes $(7,12,13)$. Systolic dysfunction is not believed to play an important role until late in the disease when a dilated cardiomyopathy may develop (14-16).

Since 1981 , we have had the opportunity to study ventricular muscle isolated from the hearts of five patients with hypertrophic cardiomyopathy. Two of these patients underwent myomyectomy for intractable symptoms of outflow tract obstruction; three underwent cardiac transplantation for endstage heart failure. Compared with preparations from control human hearts, muscles from each of the hypertrophic cardiomyopathic hearts demonstrated both contraction and relaxation abnormalities. Using the $\mathrm{Ca}^{++}$indicator aequorin, we were able to directly determine the relationship between contractile dysfunction and abnormal intracellular calcium handling in the hypertrophic muscles.

\section{Methods}

Tissue was obtained from five patients in whom hypertrophic cardiomyopathy had been diagnosed on the basis of clinical signs and symptoms and characteristic echocardiographic and hemodynamic findings:

Patient 1. A 31-yr-old woman who underwent ventricular myomectomy in May, 1981 for symptoms of dynamic outflow tract obstruction unresponsive to medical therapy. Medications at the time of surgery included propranolol, $100 \mathrm{mg}$, and disopyramide, $100 \mathrm{mg}$, given four times daily.

Patient 2. A 49-yr-old man who underwent cardiac transplantation in July, 1985 for end-stage heart failure. Medications at the time of surgery included digoxin, furosemide, and coumadin.

Patient 3. A 45-yr-old woman who underwent cardiac transplantation in January, 1986 for end-stage heart failure. Medications at the time of surgery included furosemide, spironolactone, metolazone, and coumadin.

Patient 4. A 19-yr-old woman who underwent cardiac transplantation in November, 1987 for end-stage heart failure. Medications at the time of surgery included digoxin, chlorothiazide, coumadin, quinidine, and captopril.

Patient 5. A 69-yr-old woman who underwent myomectomy in January, 1989 for symptoms of dynamic outflow tract obstruction 
Table I. Hemodynamic Values of Patients with Hypertrophic Cardiomyopathy

\begin{tabular}{|c|c|c|c|c|c|c|c|c|}
\hline $\begin{array}{l}\text { Patient } \\
\text { No. }\end{array}$ & $\begin{array}{l}\text { Days } \\
\text { PTS }\end{array}$ & RA & PA & $\mathrm{PCW}$ & LV, apex & LV, base & ASC aorta & $\mathrm{CI}$ \\
\hline & & $\mathrm{mmHg}$ & $m m H g$ & $\mathrm{mmHg}$ & $m m H g$ & $m m H g$ & $m m H g$ & liter/min per $M$ \\
\hline 1 & 30 & 8 & 34 & 27 & $186 / 27$ & $84 / 21$ & $84 / 56$ & 2.5 \\
\hline 2 & 150 & 25 & 36 & 30 & $92 / 29$ & - & - & 2.2 \\
\hline 3 & 97 & 19 & 24 & 20 & $90 / 18$ & $90 / 18$ & $90 / 62$ & 1.6 \\
\hline 4 & 47 & 9 & 13 & 15 & - & - & - & 1.5 \\
\hline 5 & 5 & 6 & 20 & 12 & $176 / 12$ & - & $158 / 65$ & 2.7 \\
\hline
\end{tabular}

Days PTS, days prior to surgery; RA, right atrial pressure; PA, pulmonary artery pressure; PCW, pulmonary capillary wedge pressure; LV, left ventricular pressure; ASC aorta, ascending aorta pressure; $\mathrm{CI}$, cardiac index; LVEF, left ventricular ejection fraction; MR, mitral regurgitation; and WNL, within normal limits.

unresponsive to medical therapy. Medications at the time of surgery included diltiazem, $60 \mathrm{mg}$ given four times daily, disopyramide, 100 mg given four times, metoprolol, $50 \mathrm{mg}$ given twice, nifedipine, $10 \mathrm{mg}$ given three times, isosorbide, and insulin.

Hemodynamic values for these patients before surgery are listed in Table I. Experimental preparations included thin trabeculae carneae $(n$ $=16$ ) with mean fiber diameters of $0.93 \pm 0.30 \mathrm{~mm}$, and an accessory papillary muscle $(n=1)$.

Results obtained with trabeculae carneae were compared with those obtained with trabeculae carneae isolated from the hearts of eight brain-dead organ donors without cardiac dysfunction (mean fiber diameters, $1.03 \pm 0.05 \mathrm{~mm} ; n=25$ ). In all cases, experimental tissue was placed after excision into a container of oxygenated physiologic salt solution (see composition below) at room temperature. 9 of the 16 muscles in the hypertrophic cardiomyopathic group and 10 of the 25 muscles in the control group were obtained from the left ventricle; the remainder were obtained from the right ventricle. Due to the similarity of results, left and right ventricular preparations were analyzed together. We have previously reported that there are no differences in contractile performance in muscles obtained from the left or right ventricle (19). The muscle from patient 1 was excluded from group analysis due to the slightly different composition of the superfusate. The composition of the solution used to superfuse muscle from patient 1 was as follows (concentrations in $\mathrm{mEq} /$ liter): $\mathrm{Na}^{+}, 140 ; \mathrm{K}^{+}, 5 ; \mathrm{Ca}^{++}$, 2.25; $\mathrm{Mg}^{++}, 2 ; \mathrm{Cl}^{-}, 103.5 ; \mathrm{HCO}_{3}^{-}, 24 ; \mathrm{HPO}_{4}^{-}, 2 ; \mathrm{SO}_{4}^{-}, 2$; acetate ${ }^{-}, 20$; plus $10 \mathrm{mM}$ /liter glucose. For all remaining studies the composition of the superfusate was as follows $(\mathrm{mM}): \mathrm{Na}^{+}, 146.2 ; \mathrm{K}^{+}, 5,9 ; \mathrm{Ca}^{++}, 2.5$; $\mathrm{Mg}^{++}, 2.4 ; \mathrm{Cl}^{-}, 133.3 ; \mathrm{HCO}_{3}^{-}, 25 ; \mathrm{H}_{2} \mathrm{PO}_{4}^{-}, 1.2$, plus glucose, $11.5 \mathrm{mM} /$ liter. Although slightly different, both solutions contained bicarbonate buffers and similar concentrations of $\mathrm{Ca}^{++}$and $\mathrm{Mg}^{++}$(key ions). Solutions were bubbled with $95 \% \mathrm{O}_{2}$ and $5 \% \mathrm{CO}_{2}$ to achieve a pH of 7.4. Phosphate was removed from the solution during performance of calcium concentration-response curves in order to prevent precipitation of calcium phosphate. Muscles were placed in organ baths at 30 or $38^{\circ} \mathrm{C}$, connected to transducers for recording tension, and were stimulated to contract at 0.25 or $0.33 \mathrm{~Hz}$, through punctate electrodes using voltage that was $\leq 10 \%$ above threshold with pulse durations of $5 \mathrm{~ms}$. Muscles were superfused in the bath for $1-1.5 \mathrm{~h}$ during which time they were stretched to the length at which maximal isometric tension developed.

Intracellular calcium transients were recorded with aequorin, a bioluminescent indicator that emits light when it combines with $\mathrm{Ca}^{++}$. The preparation of aequorin for laboratory use and the kinetics of its reaction with $\mathrm{Ca}^{++}$have been described in detail (17). Aequorin was loaded into hypertrophic cardiomyopathic muscles by microinjection (17) or a chemical technique (18). We have demonstrated that there is qualitatively no difference in the detected aequorin signal with either technique (20). Light and tension responses were recorded simultaneously. Light signals were recorded with a photomultiplier (EMI 9635 $\mathrm{qA}$ ) and signals averaged to obtain a satisfactory signal-to-noise ratio.
Action potentials were recorded with fine-tipped straight microelectrodes made of borosilicate glass. Electrodes were filled with $\mathrm{KCl} 3 \mathrm{M}$, and connected to an electrometer. Before making experimental recordings several twitches were recorded under steady-state conditions in order to confirm stable impalement (21).

Histologic measurements were performed on experimental tissue stained with hemotoxylin and eosin, embedded in plastic, and sectioned at $1-2 \mu \mathrm{m}$. The length and width of 10 fibers per trabecular strip were measured at the site of a centrally located nucleus. Nuclear area was calculated using the formula (semiaxis $A \times$ semiaxis $B$ ) $\times$ pi. Statistical comparisons were made by Students $t$ test and $P$ values $<0.05$ were considered significant.

\section{Results}

Since prolonged diastolic relaxation is the most frequently reported abnormality of contractile function in hypertrophic cardiomyopathy, we compared the time courses of isometric contraction and relaxation in trabeculae carneae from control cardiac muscle versus cardiac muscle from patients with hypertrophic cardiomyopathy. Table II shows that at an extracellular $\mathrm{Ca}^{++}$concentration $\left(\left[\mathrm{Ca}^{++}\right]_{0}\right)^{1}$ of 1 or $16 \mathrm{mM}$, the time to $50 \%$ relaxation from peak tension $\left(\mathrm{RT}_{50}\right)$ and time to $80 \%$ relaxation from peak tension $\left(\mathrm{RT}_{\mathbf{8 0}}\right)$ in the hypertrophic cardiomyopathic trabeculae carneae were significantly prolonged compared with the controls. Moreover, hypertrophic cardiomyopathic muscles showed a progressive increase in the time course of relaxation as $\left[\mathrm{Ca}^{++}\right]_{0}$ was increased that was much more marked than in the controls.

Because the hypertrophic cardiomyopathic trabeculae described in Table II were removed from patients with end-stage heart failure, we were surprised to find that they were able to generate similar or greater peak isometric tension, as normal myocardium from the controls. It should be noted that the values included in Table II were obtained under relatively hypothermic conditions (i.e., temperature $=30^{\circ} \mathrm{C}$ ) and at a low frequency of stimulation (i.e., 20 twitches/min). To investigate whether this observation might be an artifact of temperature and stimulation rate we also studied muscles at $38^{\circ} \mathrm{C}$ and physiologic frequencies of stimulation. As shown in Fig. 1 at stimulation frequencies of $1 \mathrm{~Hz}$ or greater, active tension development was less than at lower frequencies. This frequency-related decrease in active tension development (Fig. $1 A$ ) was associated with a corresponding increase in end-diastolic tension (Fig. 1

1. Abbreviations used in this paper: $\left[\mathrm{Ca}^{++}\right]_{\mathrm{i}, \mathrm{o}}$, intracellular, extracellular $\mathrm{Ca}^{++}$concentration. 
Table II. Amplitudes and Time Courses of Twitches in Control and Hypertrophic Cardiomyopathic Muscles

\begin{tabular}{lcccccc}
\hline & {$\left[\mathrm{Ca}^{++}\right]_{0}$} & $\mathrm{~N}$ & $\mathrm{PT}$ & $\mathrm{TPT}$ & $\mathrm{RT}_{\text {s0 }}$ & $\mathrm{RT}_{\mathbf{8 0}}$ \\
\hline & $M$ & & $m N / m m^{2}$ & $m s$ & $m s$ & \\
Control & 1 & 22 & $3.7 \pm 1.5$ & $317 \pm 20$ & $258 \pm 16$ & $435 \pm 33$ \\
& 16 & 24 & $12.6 \pm 5.4$ & $348 \pm 12$ & $300 \pm 35$ & $485 \pm 60$ \\
HCM & 1 & 8 & $9.1 \pm 3.2^{*}$ & $489 \pm 44^{*}$ & $350 \pm 45^{*}$ & $579 \pm 85^{*}$ \\
& 16 & 8 & $21.8 \pm 6.5^{*}$ & $406 \pm 46^{*}$ & $475 \pm 62^{*}$ & $826 \pm 111^{*}$
\end{tabular}

Perfusate contained 1 or $16 \mathrm{mM}\left[\mathrm{Ca}^{++}\right]_{0}$ at $30^{\circ} \mathrm{C}$ and 3-s intervals of stimulation. N, number of trabeculae studied; HCM, hypertrophic cardiomyopathy; PT, peak isometric tension; TPT, time to peak tension; $\mathrm{RT}_{50,80}$, time to $50,80 \%$ relaxation from peak tension, respectively. Values are mean \pm SE. ${ }^{*}$ For all HCM values, $P<0.05$ compared with the controls.

$B)$. Both the decrease in active tension and increase in end-diastolic tension were exacerbated by increases in $\left[\mathrm{Ca}^{++}\right]_{0}$. Similar abnormalities in active and end-diastolic tension development were seen at higher rates of stimulation in muscles from all five patients with hypertrophic cardiomyopathy and were present at $30^{\circ} \mathrm{C}$ as well as $38^{\circ} \mathrm{C}$.

We used aequorin-loaded trabeculae carneae to test directly whether the systolic and diastolic abnormalities we observed were due to changes in intracellular $\mathrm{Ca}^{++}\left(\left[\mathrm{Ca}^{++}\right]_{i}\right)$ handling. Fig. 2 shows the tension and light (i.e., $\left[\mathrm{Ca}^{++}\right]_{\mathrm{i}}$ ) recordings in a trabecular strip from a patient with hypertrophic cardiomyopathy (bottom) and a control trabecular strip (top) at $2.5 \mathrm{mM}$ $\left[\mathrm{Ca}^{++}\right]_{0}$. The figure shows that the $\left[\mathrm{Ca}^{++}\right]_{\mathrm{i}}$ transient in control muscle consists of a single component that rapidly rises to a peak and declines towards baseline. In contrast, the $\left[\mathrm{Ca}^{++}\right]_{\mathrm{i}}$ transient in hypertrophic cardiomyopathic muscle is greatly prolonged and consists of two components, labeled $L_{1}$ and $L_{2}$ in Fig. 2. Fig. 3 shows similar recordings in trabeculae at 16 $\mathrm{mM}\left[\mathrm{Ca}^{++}\right]_{0}$. Note that in both the control and hypertrophic cardiomyopathic trabeculae carneae, increasing the frequency of stimulation produced an increase in the amplitude of the $\mathrm{Ca}^{++}$transient. However, in contrast to control muscles, higher frequencies of stimulation of hypertrophic cardiomyopathic muscle resulted in fusion of the $\mathrm{Ca}^{++}$transients and twitches, and an increase in end-diastolic $\left[\mathrm{Ca}^{++}\right]_{i}$ and tension relative to lower frequencies. Note that in the presence of elevated $\left[\mathrm{Ca}^{++}\right]_{0}$ (i.e., $16 \mathrm{mM}\left[\mathrm{Ca}^{++}\right]_{0}$; Fig. 3), active tension declined at the higher frequencies of stimulation in hypertrophic cardiomyopathic muscles although total force was greater (Fig. $3 A$ ). This did not occur in control muscles (Fig. $3 \mathrm{~B}$ ).

Most positive inotropic agents, including increased $\left[\mathrm{Ca}^{++}\right]_{0}$, digitalis, and beta-adrenergic agonists, act to increase the amplitude of the $\mathrm{Ca}^{++}{ }_{i}$ transient associated with contraction. Fig. 4 shows the effects of isoproterenol on light and tension recordings in a hypertrophic cardiomyopathic muscle. $A$ Shows the effects of isoproterenol on the amplitudes of the $\mathrm{Ca}^{++}{ }_{i}$ transient and isometric twitch; in $B$, signals have been adjusted to equal amplitudes and superimposed so that time courses can be compared directly. Before administering drug, the aequorin signal consisted of two components. Isoproter-
A.

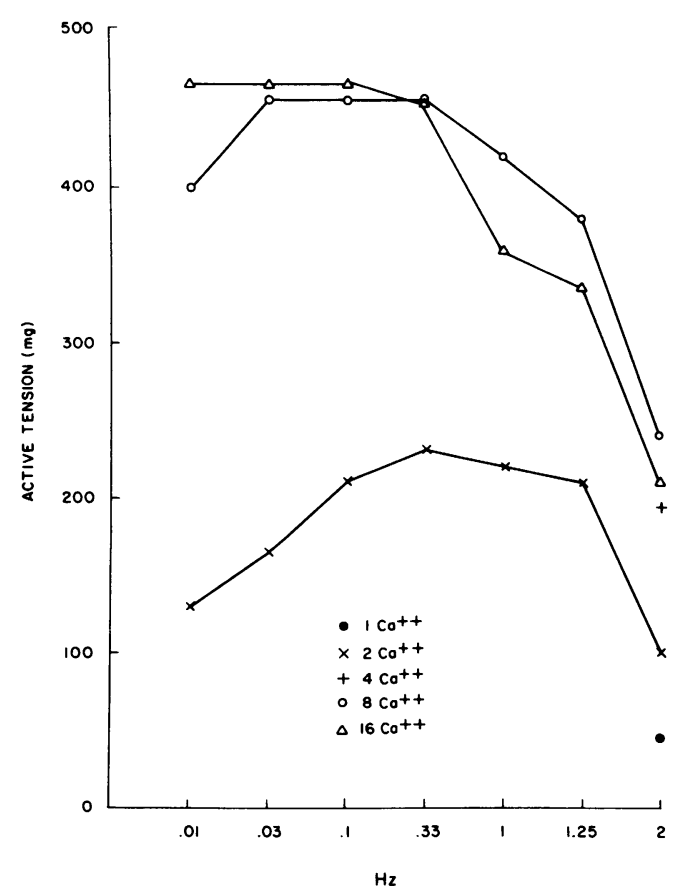

B.

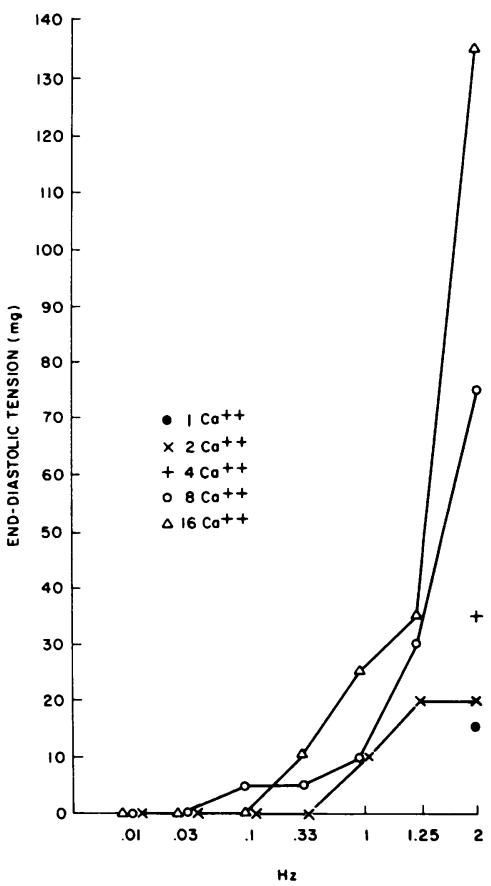

Figure 1. Effects of changes in stimulation frequency and $\left[\mathrm{Ca}^{++}\right]_{0}$, on active $(A)$ and end-diastolic $(B)$ tension development in a trabecula from patient 3 . Temperature $=38^{\circ} \mathrm{C}$; tension expressed in milligrams $(\mathrm{mg}),\left[\mathrm{Ca}^{++}\right]_{0}$ in millimolar, and stimulation frequency in hertz $(\mathrm{Hz})$. Propranolol, $6 \times 10^{-7} \mathrm{M}$ in bath. 
A
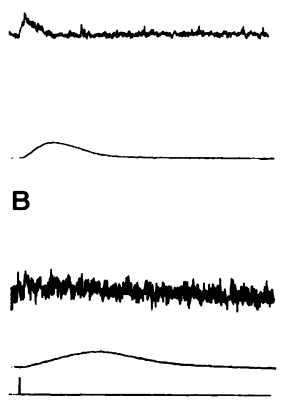

$\overline{500 \mathrm{~ms}}$
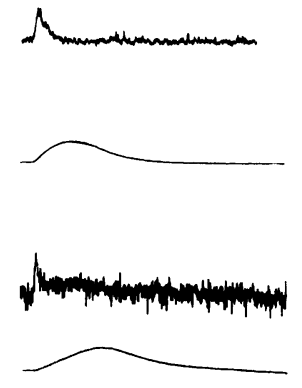

\section{.1}

\section{3}
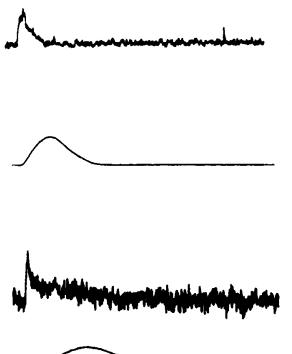

1

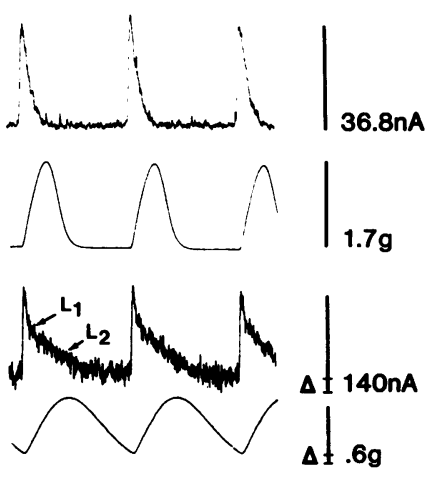

Figure 2. Light and tension responses to varying frequencies of stimulation from 0.03 to $1 \mathrm{~Hz}$ in control $(A)$ and hypertrophic trabecula $(B)$ from patient 3. Light intensity expressed in nanoAmperes (nA) and tension in grams (g). Temperature $=30^{\circ} \mathrm{C}$; $\left[\mathrm{Ca}^{++}\right]_{0}=2.5 \mathrm{mM}$. Note the two components of the $\mathrm{Ca}^{++}$transient in the hypertrophic cardiomyopathic muscle, labeled $L_{1}$ and $L_{2}$ in bottom right panel. Deltas indicate rise in end-diastolic $\mathrm{Ca}^{++}$or tension that occurs at faster pacing frequencies compared with $0.03 \mathrm{~Hz}$.

enol, which increases intracellular cAMP concentrations, not only increased the amplitude of the $\mathrm{Ca}^{++}$transient but markedly abbreviated its time course. These changes were associated with a positive inotropic effect; however, isoproterenol, in contrast to elevations in $\left[\mathrm{Ca}^{++}\right]_{0}$ (Table II) and strophanthidin (data not shown), markedly abbreviated isometric contraction and relaxation.

Fig. 5 shows the effects of a cardiotonic steroid (acetylstrophanthidin, a $\mathrm{Na}^{+}-\mathrm{K}^{+}$ATPase inhibitor) and an agent that in- creases intracellular cAMP (forskolin, an adenylate cyclase activator) on the frequency-response relationship in a hypertrophic cardiomyopathic muscle. Note that acetylstrophanthidin exacerbated, and forskolin attenuated the decrease in active tension and increase in end-diastolic tension that occurred at higher frequencies of stimulation in $16 \mathrm{mM}\left[\mathrm{Ca}^{++}\right]_{0}$.

Fig. 6 shows the effects of the calcium channel-blocking agent, verapamil, on the light and tension responses in another hypertrophic cardiomyopathic muscle. Verapamil decreased
A

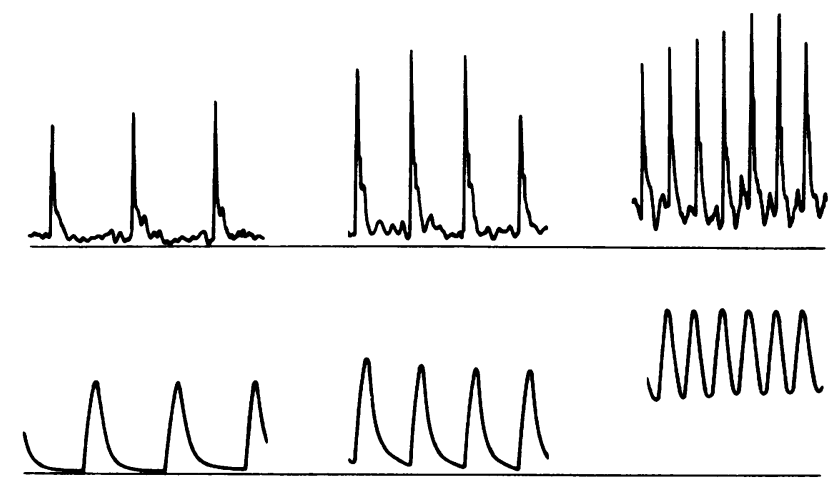

B
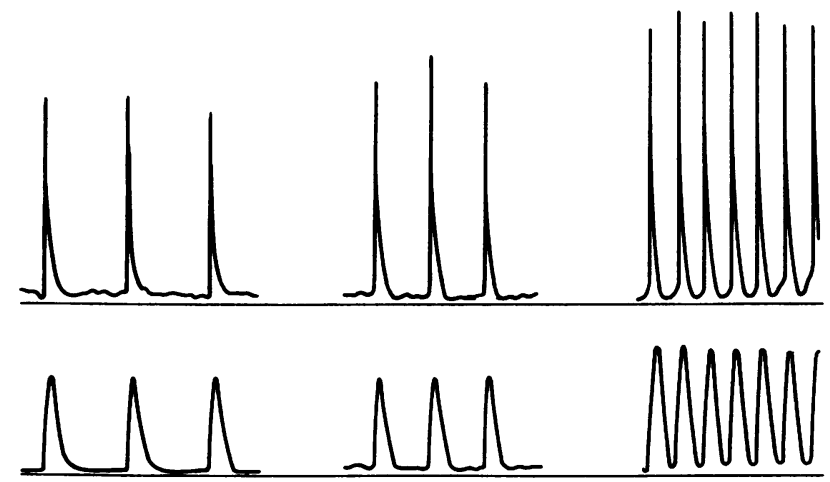

$.33 \mathrm{~Hz}$
70nA

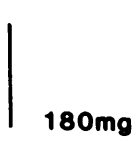

$180 \mathrm{mg}$

Figure 3. Light and tension responses to varying frequencies of stimulation from 0.33 to $1 \mathrm{~Hz}$ in a hypertrophic trabecular strip $(A)$ from patient 3 and a control trabecular strip $(B)$. Light intensity expressed in nanoAmperes $(\mathrm{nA})$, tension in milligrams (mg). Temperature $=30^{\circ} \mathrm{C}$; $\left[\mathrm{Ca}^{++}\right]_{0}=16 \mathrm{mM}$. 
A.
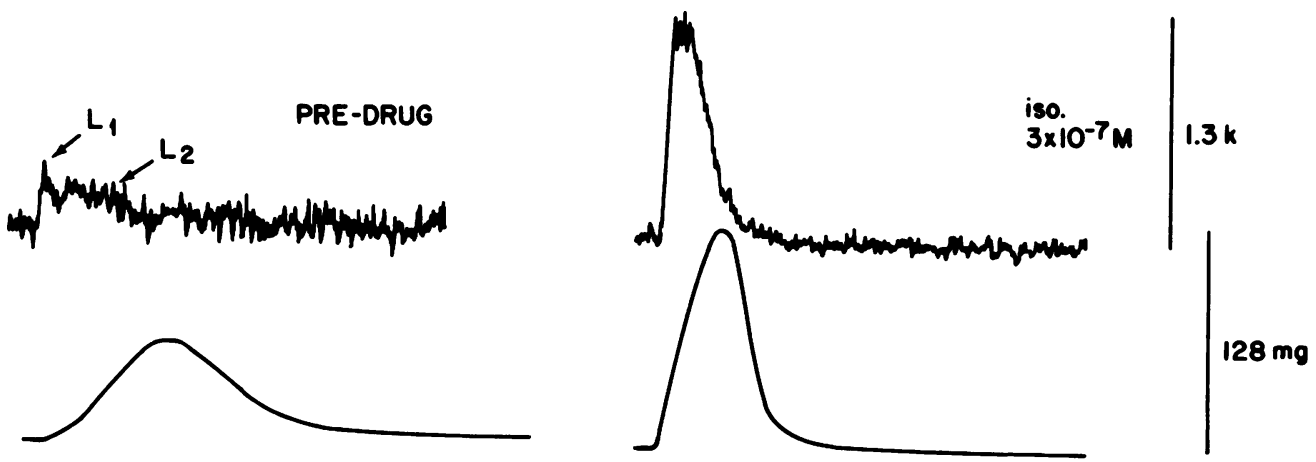

Figure 4. Light and tension responses to isoproterenol of a papillary muscle from patient 1 . A Shows effects on amplitudes of light and tension responses. In $B$, amplitudes have been adjusted to be approximately equal so that time courses can be compared directly.

B.

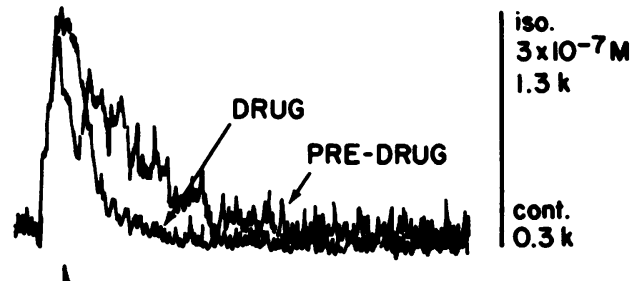

$\rightarrow 1 \quad 1-100 \mathrm{~ms}$

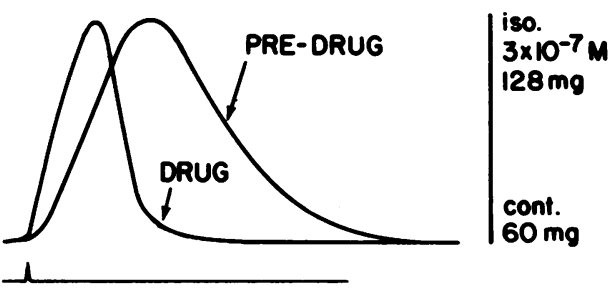

Absolute amplitude is indicated to the right of each panel. Stimulus frequency $=0.25 \mathrm{~Hz} ; 38^{\circ} \mathrm{C}$. Light is recorded with photon counter and expressed in kilocounts (k) per second (s); $\left[\mathrm{Ca}^{++}\right]_{0}$ $=2.25 \mathrm{mM}$. Stimulus artifact indicated beneath each panel.

the amplitude of both components of the aequorin light signal but did not significantly abbreviate its time course or the duration of the isometric twitch. Verapamil prevented the rise in end-diastolic tension from occurring at higher frequencies of stimulation (Fig. $7 \mathrm{~B}$ ), and produced a negative inotropic effect (Fig. 7 A).

Fig. 8 shows the effects of caffeine on the light and tension responses of a hypertrophic cardiomyopathic muscle. Note that caffeine produced a dose-related negative inotropic effect under the conditions of this experiment that was associated with a marked decrease in the amplitude of $L_{1}$; in contrast, the amplitude of $L_{2}$ was diminished to a lesser extent in response to caffeine.
Resting membrane potentials and the peak amplitude of the action potentials were not different in the control versus hypertrophic muscles. However, the time to $90 \%$ repolarization $\left(\mathrm{ADP}_{90}\right)$ and the plateau phase of the action potential were prolonged in the hypertrophic muscles $\left(\mathrm{ADP}_{90}=650 \pm 0.0 \mathrm{~ms}\right.$; $n=2)$ versus the controls $(529 \pm 39 \mathrm{~ms} ; n=3)$.

In order to determine the degree of hypertrophy in the muscles of the present series, we measured myocyte diameters and calculated nuclear areas for the hypertrophic cardiomyopathic preparations and controls. The muscle from patient 1 was not available for examination, but it is important to note that all hearts showed evidence of significant hypertrophy on the basis of electrocardiographic and echocardiographic findings. Val-
A.

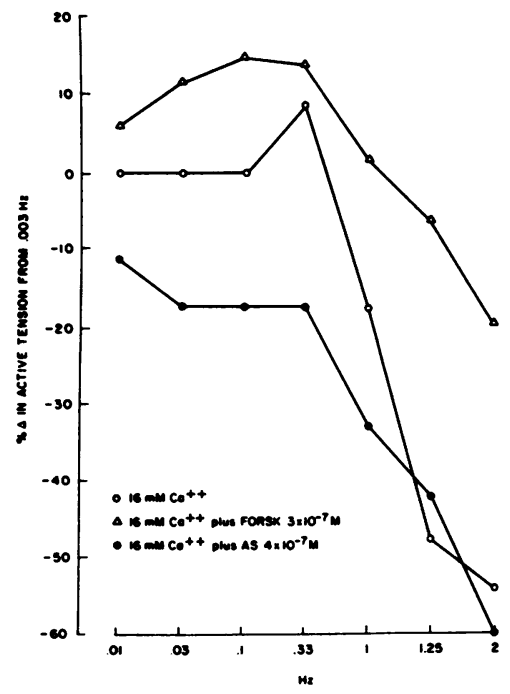

B.

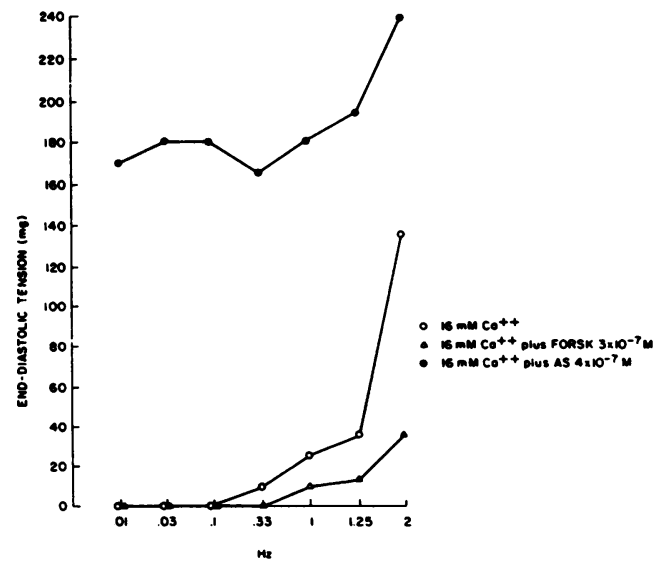

Figure 5. Effects of forskolin (FORSK) and acetylstrophanthidin $(A S)$ on the frequency-response relationship and active and end-diastolic tension development in a trabecular strip from patient 3 . Values for active tension expressed as percentage change from baseline defined at $0.03 \mathrm{~Hz}$. Temperature $=38^{\circ} \mathrm{C} ;\left[\mathrm{Ca}^{++}\right]_{0}$ $=16 \mathrm{mM}$; propranolol, $6 \times 10^{-7} \mathrm{M}$ present in bath. 
A.

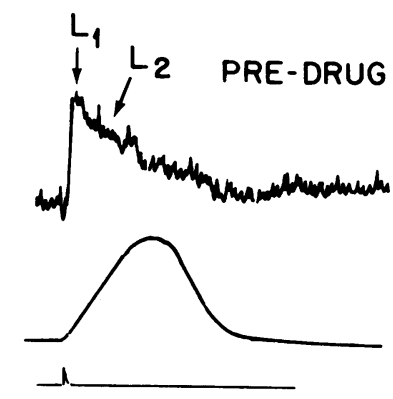

B.

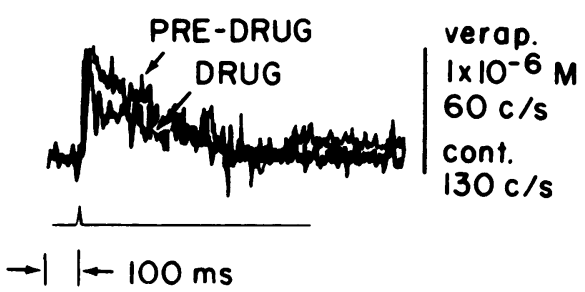

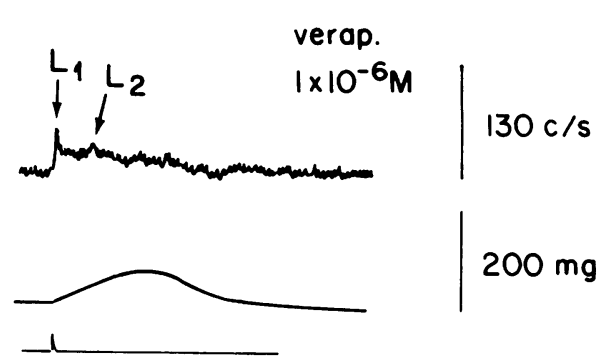

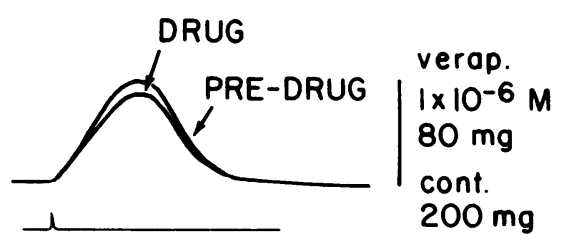

Figure 6. Light and tension responses to verapamil of a papillary muscle from patient $1 . A$ Shows effects on amplitudes of light and tension responses. In $B$, amplitudes have been adjusted to be approximately equal so that time courses can be compared directly. Absolute amplitude is indicated to the right of each panel. Stimulus frequency $=0.25 \mathrm{~Hz} ; 38^{\circ} \mathrm{C}$ Light is recorded with photon counter and expressed in counts/second $(\mathrm{c} / \mathrm{s})$; tension in milligrams $(\mathrm{mg}) ;\left[\mathrm{Ca}^{++}\right]_{0}$ $=2.25 \mathrm{mM}$. Stimulus artifact indicated beneath each panel. ues for the control $(n=18)$ and hypertrophic cardiomyopathic $(n=8)$ groups were, respectively, fiber diameter $(\mu \mathrm{m})$ $=14.6 \pm 0.36$ vs. $28.7 \pm 0.36, P \leq 0.001$; and nuclear area $\left(\mu \mathrm{m}^{2}\right)$ $=58.1 \pm 2$ vs. $82.3 \pm 6.2, P \leq 0.001$.

\section{Discussion}

Heart failure can occur as a result of systolic dysfunction, diastolic dysfunction, or a combination of both. In this study, working myocardium from patients with hypertrophic cardiomyopathy demonstrated marked abnormalities of diastolic relaxation compared with controls, under a variety of conditions. Systolic function (i.e., active tension development) was normal or supranormal at lower frequencies of stimulation when sufficient time elapsed between twitches for complete relaxation to occur (Table II). However, at faster, more physiologic rates of stimulation, fusion of the $\mathrm{Ca}^{++}$transients and corresponding mechanical responses occurred, leading to an increase in enddiastolic $\left[\mathrm{Ca}^{++}\right]_{\mathrm{i}}$ and an associated increase in end-diastolic tension and a decrease in active tension development. This occurred in cardiac muscle from hypertrophic cardiomyopathy patients with and without clinical evidence of heart failure, but not in controls. It is important to note that these abnormalities may reflect purely diastolic dysfunction with normal intrinsic systolic function, in which case the decrease in active tension at high end-diastolic tensions would reflect the expected lengthtension relationship. Whether or not systolic function is fully "normal" or to some degree impaired is uncertain; however, the diastolic abnormalities are clearly the more important of the two. These results suggest that hypertrophic cardiomyopathy is a pathophysiologic state in which diastolic dysfunction, in part due to cytosolic $\mathrm{Ca}^{++}$overload, can markedly depress active force generation during systole, an observation that has important therapeutic implications.

The force per cross-sectional area generated by the hypertrophic preparations was significantly greater than the control at normal and maximally activating $\left[\mathrm{Ca}^{++}\right]_{0}$, as shown in Table II. The force generated by these muscles is also significantly greater than the average for muscles from the hearts of patients undergoing transplantation for end-stage cardiomyopathy, which we have found to be similar to that of controls at a $0.33-\mathrm{Hz}$ stimulation frequency, $30^{\circ} \mathrm{C}, 2.5$ or $16 \mathrm{mM}\left[\mathrm{Ca}^{++}\right]_{\mathrm{o}}$

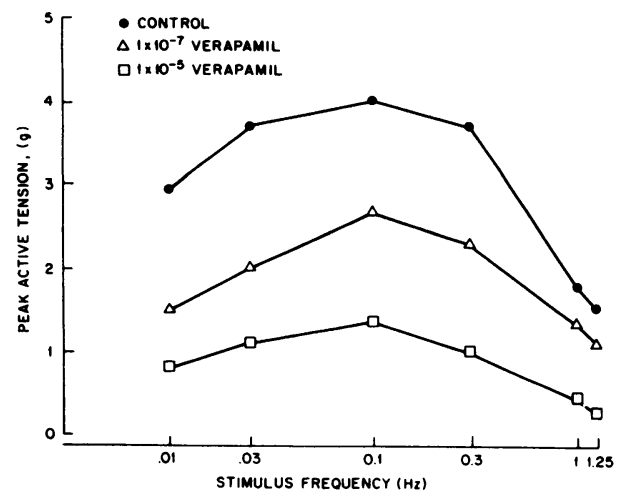

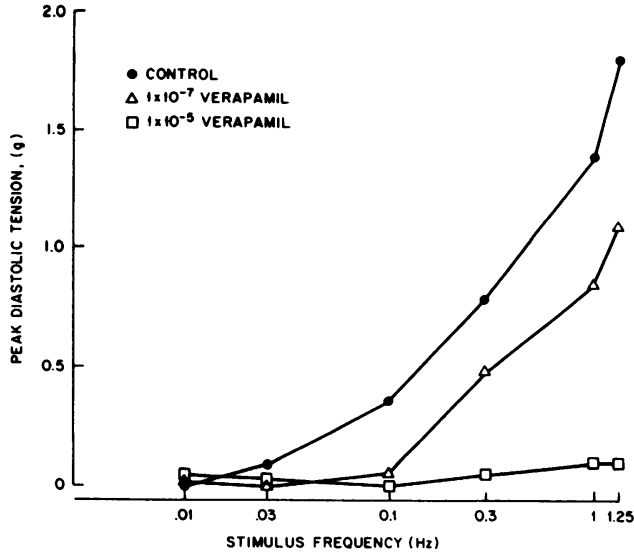

Figure 7. Effects of verapamil on the frequencyresponse relationship and active $(A)$ and end-diastolic $(B)$ tension development in a trabecular strip from patient 3 . Propranolol, $6 \times 10^{-7} \mathrm{M}$ present in the bath; $\left[\mathrm{Ca}^{++}\right]_{\mathrm{o}}=2.5 \mathrm{mM} ; 30^{\circ} \mathrm{C}$. 

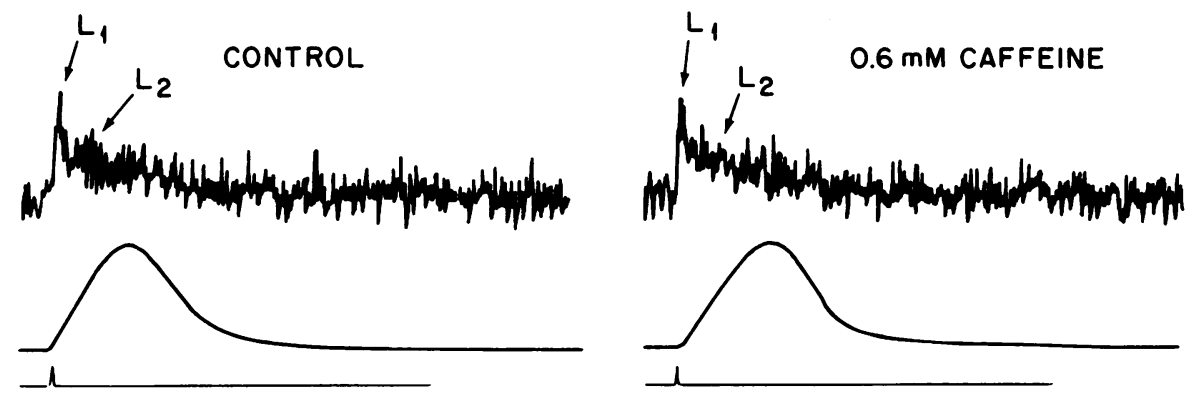

$2 \mathrm{mM}$ CAFFEINE

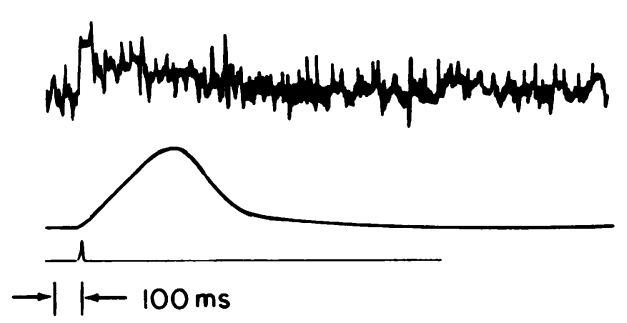

Figure 8. Effects of caffeine on the light and tension responses of a papillary muscle from patient 1 . In each panel, upper trace $=$ light in photon counts/second $(c /$ $s)$; middle trace $=$ tension in milligrams (mg); the lower trace is the stimulus artifact. Doses of caffeine expressed in millimolar; stimulus frequency $=0.25 \mathrm{~Hz} ;\left[\mathrm{Ca}^{++}\right]_{0}=2.25$ $\mathrm{mM}$.
$(21,22)$. The reason for this apparent increase in force generating capacity is unclear, but does not appear to be due to the hypothermic conditions of our experiments and is not manifest at higher pacing rates where diastolic dysfunction develops (see Results). Individual myocyte diameter was significantly greater in the hypertrophic muscle of the present series compared with those from control hearts or hearts from patients with endstage dilated cardiomyopathy (see Results and reference 21). Since the myofibrillar content of hypertrophied fibers is increased, it is possible that the favorable energetic state and adequate restitution time for $\left[\mathrm{Ca}^{2+}\right]_{\mathrm{i}}$ that exist under the basal condition of our experiments allow this increase in contractile protein content to become functionally manifest as an increase in peak and maximally activated twitch force.

As shown in Table II and Figs. 1 and 3, contractile abnormalities of the hypertrophic cardiomyopathic muscles were exacerbated by increasing $\left[\mathrm{Ca}^{++}\right]_{0}$, which indicates an inability to maintain intracellular $\mathrm{Ca}^{++}$homeostasis $(21,23)$. Digitalis (i.e., strophanthidin and acetylstrophanthidin) exacerbated systolic and diastolic dysfunction (Fig. 5) by increasing $\left[\mathrm{Ca}^{++}\right]_{\mathrm{i}}$ via transsarcolemmal $\mathrm{Na}^{+}-\mathrm{Ca}^{++}$exchange, which occurs as a result of $\mathrm{Na}^{+}-\mathrm{K}^{+}$ATPase inhibition (24). In contrast, although isoproterenol and forskolin also increased $\left[\mathrm{Ca}^{++}\right]_{i}$, as judged from the amplitude of the aequorin light signal (Fig. 4), diastolic dysfunction in hypertrophic cardiomyopathic muscles was reversed towards normal (Fig. 5). This apparently occurred as a result of the positive lusitropic actions of these drugs, which increase $[\mathrm{cAMP}]_{\mathrm{i}}$ and enhance the ability of the sarcoplasmic reticulum to sequester calcium and lower $\left[\mathrm{Ca}^{++}\right]_{i}(25,26)$. These data suggest that drugs with positive lusitropic actions may be useful agents for correcting the cellular abnormalities that underlie myocardial dysfunction of hypertrophic cardiomyopathy, and that agents with negative lusitropic actions should be avoided. In clinical practice, however, these factors must be balanced against the demonstrated utility of drugs with negative inotropic and chronotropic properties, such as the beta-adrenoceptor antagonists and verapamil, to reverse hy- percontractile function and increase diastolic filling time in patients with hypertrophic cardiomyopathy $(27,28)$. In addition, drugs that increase cAMP also increase transsarcolemmal $\mathrm{Ca}^{++}$entry and might, under some circumstances, exacerbate $\left[\mathrm{Ca}^{++}\right]_{\mathrm{i}}$ overload. Although verapamil did not significantly abbreviate the time course of the $\mathrm{Ca}^{++}$transient or isometric contraction, it decreased the amplitude of both components of the $\mathrm{Ca}^{++}$transient and prevented the increase in end-diastolic tension from occurring at higher frequencies of stimulation (Fig. 7 $B)$. These results are consistent with reports in the clinical literature documenting hemodynamic improvement of patients with hypertrophic cardiomyopathy after administration of $\mathrm{Ca}^{++}$channel blocking agents $(7,29-32)$. It must also be remembered that in clinically relevant doses, each of these agents has significant positive (i.e., isoproterenol) or negative (i.e., cardiac glycosides, beta-adrenoceptor antagonists, and verapamil) chronotropic actions that can have important effects in view of the frequency dependency of myocardial dysfunction in this pathophysiologic state.

Abnormal $\mathrm{Ca}^{++}$handling may occur at several cellular sites, including the sarcolemma, sarcoplasmic reticulum, mitochondria, and troponin complex (33). Our previous studies have indicated that the $\mathrm{Ca}^{++}$transient recorded with aequorin in control human myocardium consists of a single component that reflects the release and uptake of $\mathrm{Ca}^{++}$by the sarcoplasmic reticulum (34). In contrast, the $\mathrm{Ca}^{++}$transient recorded in muscle from patients with hypertrophic cardiomyopathy, or dilated cardiomyopathy with significant compensatory hypertrophy, consists of two distinct components, labeled $L_{1}$ and $L_{2}$ in Fig. 2. $L_{1}$ appears to reflect $\mathrm{Ca}^{++}$released from the sarcoplasmic reticulum and $L_{2}$ a combination of $\mathrm{Ca}^{++}$release from the sarcoplasmic reticulum and $\mathrm{Ca}^{++}$entering the cell via voltagedependent sarcolemmal $\mathrm{Ca}^{++}$channels (21).

To further investigate the role of enhanced transsarcolemmal influx of $\mathrm{Ca}^{++}$, we studied the electrophysiologic properties of control and hypertrophic muscles. Representative action potentials from control and myopathic muscles, including one of 
the hypertrophic preparations in this report, are shown in Fig. 2 of reference 21 . The prolonged repolarization and plateau phase of the action potentials recorded from hypertrophic muscles suggest that there may be enhanced $\mathrm{Ca}^{++}$influx across the sarcolemma. Possible mechanisms may involve an increase in the number of calcium channels as reported for the hypertrophic cardiomyopathic Syrian hamster (35) or enhanced conductance through existing channels. An increase in the number of dihydropyridine binding sites has been demonstrated in atrial tissue from patients with hypertrophic cardiomyopathy, suggesting enhanced transsarcolemmal calcium influx through voltage-dependent calcium channels (36). This concept has recently been challenged (37), however.

Caffeine is a drug that has a variety of cellular actions, including blockade of uptake, and subsequently release, of $\mathrm{Ca}^{++}$ from the sarcoplasmic reticulum, inhibition of phosphodiesterase with a consequent increase in [cAMP $]_{i}$, and sensitization of the myofilaments to $\mathrm{Ca}^{++}(38-40)$. As shown in Fig. 8, caffeine's effects on the sarcoplasmic reticulum appear predominant, since the drug produced a dose-related negative inotropic effect that was associated with a decrease in the amplitude of $L_{1}$ and a less pronounced decrease in the amplitude of $L_{2}$. These effects are similar to those reported previously for ryanodine, an agent that selectively blocks release of $\mathrm{Ca}^{++}$from the sarcoplasmic reticulum (21). In contrast, caffeine and the related methylxanthine theophylline, produce a positive inotropic effect in normal human myocardium under similar experimental conditions (34). Similar negative inotropic actions of caffeine have been described in muscle from patients with endstage dilated cardiomyopathy and compensatory hypertrophy and may be a reflection of deficient production of cyclic nucleotides in hypertrophic cardiomyopathic muscle, which prevents the phosphodiesterase-inhibiting properties of caffeine from becoming manifest (22). Since cAMP plays an important role in modulating the entry of $\mathrm{Ca}^{++}$via voltage-dependent sarcolemmal calcium channels, the uptake of $\mathrm{Ca}^{++}$by the sarcoplasmic reticulum and $\mathrm{Ca}^{++}$sensitivity of the troponin complex (25), it is reasonable to speculate that abnormal $\mathrm{Ca}^{++}$handling and contractile dysfunction in hypertrophic cardiomyopathy may be due in part to deficient levels of cyclic nucleotides. The corrective effects of isoproterenol and forskolin support this hypothesis (Figs. 4 and 5).

We have reported abnormal $\left[\mathrm{Ca}^{++}\right]$handling, mechanical, and electrical activity in muscle from patients with end-stage dilated cardiomyopathy undergoing cardiac transplantation (21). Of interest, the muscles in that series all showed histologic evidence of significant hypertrophy compared with the controls. Similarly, in this study we report abnormalities in excitation-contraction coupling in muscles from patients with hypertrophic cardiomyopathy with and without end-stage heart failure. In this study, mean fiber diameters and nuclear areas were significantly greater in muscles from patients with hypertrophic cardiomyopathy compared with controls. These findings raise the important possibility that the contractile dysfunction we observed may be a reflection of the hypertrophied state per se (21).

In conclusion, these studies indicate that at physiologic temperatures and heart rates, a state of relative $\mathrm{Ca}^{++}$overload develops in ventricular muscle from patients with hypertrophic cardiomyopathy. This calcium overload results in increased end-diastolic $\left[\mathrm{Ca}^{++}\right]_{i}$, incomplete relaxation and fusion of twitches with a resultant increase in end-diastolic tension, and a decrease in active tension development. This is a clear example of a condition in which diastolic dysfunction can impair active systolic force generation and may explain why patients with hypertrophic cardiomyopathy poorly tolerate increases in heart rate.

\section{Acknowledgments}

The authors gratefully acknowledge the contributions to this study of Drs. Lawrence Cohn, John J. Collins, and James Marsh of Brigham and Women's Hospital, Dr. James Pluth of the Mayo Clinic and Foundation, the technical assistance of Mr. Norman Lee, and the medical graphics of Mr. Al Brass.

This work was supported in part by United States Public Health Service Grants HL-12186 to J. R. Blinks of the Mayo Clinic, HL07111, HL-31117, and a Research Career Development Award (HL01611) to Dr. Morgan, HL-139091, HL-07374, and HL-36797 to Dr. Gwathmey who is an Established Investigator supported in part by the American Heart Association, a Clinician-Scientist Award from the American Heart Association to Dr. Warren, a Fellowship from the American Heart Association to Dr. Phillips, and HL-07374 and a Fellowship from the American Heart Association to Dr. Briggs. Publication costs are supported in part by the Christine Anne Bohannon Endowment Fund.

\section{References}

1. Maron, B. J., and S. E. Epstein. 1980. Hypertrophic cardiomyopathy, recent observations regarding the specificity of three hallmarks of the disease: asymmetric septal hypertrophy, septal disorganization and systolic anterior motion of the anterior mitral leaflet. Am. J. Cardiol. 45:141-154.

2. Maron, B. J., R. O. Bonow, R. O. Cannon, M. B. Leon, and S. E. Epstein 1987. Hypertrophic cardiomyopathy. Interrelations of clinical manifestations, pathophysiology and therapy (Part I). N. Engl. J. Med. 316:780-789.

3. Maron, B. J., R. O. Bonow, R. O. Cannon, M. B. Leon, and S. E. Epstein. 1987. Hypertrophic cardiomyopathy. Interrelations of clinical manifestations, pathophysiology and therapy (Part II). N. Engl. J. Med. 316:844-852.

4. Braunwald, E., A. G. Morrow, W. P. Cornell, M. M. Aygen, and T. F. Hilbsin. 1960. Idiopathic hypertrophic subaortic stenoses: clinical, hemodynamic and angiographic manifestations. Am. J. Med. 29:924-945.

5. Brock, R. 1957. Functional obstruction of the left ventricle (acquired aortic subvalvar stenoses) Guy's Hosp. Rep. 106:221-238.

6. Teare, D. 1958. Assymetrical hypertrophy of the heart in young adults. $\mathrm{Br}$. Heart J. 20:1-8.

7. Lorell, B. H., W. J. Paulus, W. Grossman, J. Wynne, P. F. Cohn, and E. Braunwald. 1980. Improved diastolic function and systolic performance in hypertrophic cardiomyopathy after nifedipine. N. Engl. J. Med. 303:801-803.

8. Lorell, B. H., W. F. Paulus, W. Grossman, J. Wynne, and P. F. Cohn. 1982. Modification of abnormal left ventricular diastolic properties by nifedipine in patients with hypertrophic cardiomyopathy. Circulation. 65:499-507.

9. Cannon, R. O., D. R. Rosing, B. J. Maron, M. B. Leon, R. O. Bonow, R. M Watson, and S. E. Epstein. 1985. Myocardial ischemia in patients with hypertrophic cardiomyopathy: contribution of inadequate vasodilator reserve and elevated left ventricular filling pressures. Circulation. 71:234-243.

10. Hirota, Y., K. Furubayashi, K. Kaku, G. Shimizu, M. Kino, K. Kawamura, and T. Takatsu. 1982. Hypertrophic nonobstructive cardiomyopathy: a precise assessment of hemodynamic characteristics and clinical implications. Am. J. Cardiol. 50:990-997.

11. Sanderson, J. E., D. G. Gibson, D. J. Brown, and J. F. Goodwin. 1977. Left ventricular filling in hypertrophic cardiomyopathy. An angiographic study. Br. Heart J. 39:661-670.

12. Lorell, B. H., and W. Grossman. 1987. Cardiac hypertrophy: the consequences for diastole. J. Am. Coll. Cardiol. 9:1189-1193.

13. Kaltenbach, M., R. Hopf, and M. Keller. 1976. Calciumantag onistische therapie bei hypertroph-obstructiver kardiomyopathie. Dtsch. Med. Wochenschr. 101:1284-1287.

14. Beder, S. D., H. P. Gutgesell, C. E. Mullins, and D. G. McNamara. 1982. Progression from hypertrophic obstructive cardiomyopathy to congestive cardiomyopathy in a child. Am. Heart J. 104:155-156.

15. Shah, P. M., A. G. Adelman, and E. D. Wigle. 1974. The natural (and unnatural) history of hypertrophic obstructive cardiomyopathy. Circ. Res. 34/35(Suppl): 179-195.

16. Waller, B. F., B. J. Maron, S. E. Epstein, and W. C. Roberts. 1981. Transmural myocardial infarction in hypertrophic cardiomyopathy. A cause of conver- 
sion from left ventricular asymmetry to symmetry and from normal-sized to dilated left ventricular cavity. Chest. 79:461-465.

17. Blinks, J. R., W. G. Wier, P. Hess, and F. G. Prendergast. 1982. Measurement of $\mathrm{Ca}^{2+}$ concentrations in living cells. Prog. Biophys. Mol. Biol. 40:1-114

18. Morgan, J. P., T. T. DeFeo, and K. G. Morgan. 1984. A chemical procedure for loading aequorin into mammalian working myocardium. Pflugers Arch. Eur. J. Physiol. 400:338-340.

18. Morgan, J. P., T. T. DeFeo, and K. G. Morgan. 1984. A chemical procedure for loading aequorin into mammalian working myocardium. Pflugers Arch. Eur. J. Physiol. 400:338-340.

19. Stambler, B. S., M. D. Feldman, S. E. Warren, P. Phillips, and J. P. Morgan. 1987. Uniformity of isometric contraction between human right and left ventricular myocardium. Circulation. 76(Suppl IV):536.

20. Kihara, Y., and J. P. Morgan. 1989. A comparative study of three methods of intracellular calcium loading of the calcium indicator aequorin in ferret papillary muscles. Biochem. Biophys. Res. Commun. 162:402-407.

21. Gwathmey, J. K., L. Copelas, R. MacKinnon, F. Schoen, M. D. Feldman, W. Grossman, and J. P. Morgan. 1987. Abnormal intracellular calcium handling in myocardium from patients with end-stage heart failure. Circ. Res. 61:70-76.

22. Feldman, M. D., L. Copelas, J. K. Gwathmey, P. Phillips, S. E. Warren, F. J. Schoen, W. Grossman, and J. P. Morgan. 1987. Deficient production of cyclic AMP: pharmacologic evidence of an important cause of contractile dysfunction in patients with end-stage heart failure. Circulation. 75:331-339.

23. Morgan, J. P., and K. G. Morgan. 1984. Calcium and cardiovascular function. Intracellular calcium levels during contraction and relaxation of mammalian cardiac and vascular smooth muscle as detected with aequorin. Am. J. Med. 77(Suppl):33-46.

24. Smith, T. W. 1984. The basic mechanism of inotropic action of digitalis glyosides. J. Pharmacol. 15(Suppl):35-51.

25. Katz, A. M. 1983. Cyclic adenosine monophosphate effects on the myocardium. A man who blows hot and cold with one breath. J. Am. Coll. Cardiol. 2:143-149.

26. Opie, L. H. 1982. Role of cyclic nucleotides in heart metabolism. Cardiovasc. Res. 16:483-507.

27. Cohen, L. S., and E. Braunwald. 1967. Amelioration of angina pectoris in idiopathic hypertrophic subaortic stenoses with beta adrenergic blockade. Circulation. 35:847-851.

28. Pollick, M. B. 1982. Muscular subaortic stenosis. Hemodynamic and clinical improvement after disopyramide. N. Engl. J. Med. 307:997-998.
29. Chatterjee, K., G. Raff, D. Anderson, and W. W. Parmley, 1982. Hypertrophic cardiomyopathy - therapy with slow channel inhibiting agents. Prog. Cardiovasc. Dis. 15:193-210.

30. Hanrath, P., D. G. Mathey, P. Kremer, F. Sonntag, and W. Bleifeld. 1980. Effect of verapamil on left ventricular isovolumic relaxation time and regional left ventricular filling in hypertrophic cardiomyopathy. Am. J. Cardiol. 45:12581264.

31. Bonow, R. O., V. Dilsizian, D. R. Rosing, B. J. Maron, S. L. Bacharach, and $M$. V. Green. 1985. Verapamil-induced improvement in left ventricular diastolic filling and increased exercise tolerance in patients with hypertrophic cardiomyopathy: short- and long-term effects. Circulation. 72:853-864.

32. Lorell, B. H. 1985. Use of calcium channel blockers in hypertrophic cardiomyopathy. Am. J. Cardiol. 78(Suppl):43-54.

33. Dhalla, N. S., G. N. Pierce, V. Anagia, P. K. Singal, and R. E. Beamish 1982. Calcium movements in relation to heart function. Basic Res. Cardiol 77:117-139.

34. Morgan, J. P., J. H. Chesebro, J. R. Pluth, F. J. Puga, and H. V. Schaff. 1984. Intracellular calcium transients in human working myocardium as detected with aequorin. J. Am. Coll. Cardiol. 1984;3:410-418.

35. Wagner, J. A., I. J. Reynolds, H. F. Weisman, P. Dudeck, M. L. Weisfeldt, and S. H. Snyder. 1986. Calcium antagonist receptors in cardiomyopathic hamsters. Selective increases in heart, muscle, brain. Science (Wash. DC). 232:515518.

36. Wagner, J. A., F. L. Sax, H. F. Wesiman, J. Potterfield, C. McIntosh, M. L. Weisfeldt, S. H. Snyder, and S. E. Epstein. 1989. Calcium-antagonist receptors in the atrial tissue of patients with hypertrophic cardiomyopathy. N. Engl. J. Med. 320:755-761.

37. Sen, L., M. O'Neil, J. D. Marsh, and T. W. Smith. 1990. Inotropic and calcium kinetic effect of calcium channel agonist and antagonist in isolated cardiac myocytes from cardiomyopathic hamsters. Circ. Res. 67:599-600.

38. Blinks, J. R. C. B. Olson, B. R. Jewell, and P. Braveny, 1972. Influence of caffeine and other methylxanthines on the mechanical properties of isolated mammalian heart muscle. Circ. Res. 30:367-392.

39. Hunter, D. R., R. A. Haworth, and H. A. Berkoff. 1982. Cellular calcium turnover in the perfused rat heart: modulation by caffeine and procaine. Circ. Res. 51:363-370.

40. Wendt, I. R., and D. G. Stephenson. 1983. Effects of caffeine on Ca-activated force production in skinned cardiac and skeletal muscle fibers of the rat. Pflügers Arch. Eur. J. Physiol. 398:210-216. 